\title{
Editomia
}

\section{Transfer Pricing: The New US Regulations and the OECD Report}

\author{
Helmut Becker, Deloitte \& Touche, Düsseldorf
}

After intensive considerations and drafts in July 1994 the US regulations to Section 482 IRC became final; this is the preliminary end of a long story starting with the "commensurate with income' principle of 1986 and promoted by the White Paper of 1988. However, a new chapter of that story will follow dealing with penalties. Furthermore, some areas are still under discussion; e.g. concerning services and the $\mathrm{R}+\mathrm{D}$ cost sharing.

The final US regulations have to be seen in the context with the new OECD Discussion Draft on the same subject. A high degree of similarity cannot be denied. The big question, however, is: Who has influenced - and perhaps dominated-whom? There is no doubt that the proposed and later changes on preliminary US regulations had a great influence on the OECD. However, a lot of the European thinking has also been influenced-via the OECD tax committee and direct objections of different governments - the final version of the US rules.

A complete harmonization could not be achieved. The judgment about the profit methods is still different. And a new area of struggle is already to be seen. The requirements for an appropriate documentation and the justification of penalties are still under discussion.

The proposed US regulations dated 30 January 1992 introduced the comparable profits methods as a new transfer pricing method. If the prerequisites for the comparable uncontrolled price method for tangibles and the comparable uncontrolled transaction method for intangibles with their very narrow definitions of comparability could not be met all other price methods were combined with and had to be checked against the comparable profits method. Therefore, this method became predominant.

This development was not acceptable to the OECD. In 1993 the OECD published a very detailed report of a special task force clearly rejecting the comparable profits method. Also some governments objected against that method. Due to this the US reduced the scope of applications. However, they did not give up. The temporary regulations dated 21 January 1993, no longer combined the standard price methods with the comparable profits method but that method was established as a separate standard price method. This was heavily objected by some members of the OECD. The result is a strange compromise.

The US continue to treat the comparable profits method as a standard price method. The OECD, however, makes a distinction between the transaction-based methods - which are the comparable uncontrolled price method, the resale price method, and the cost-plus method and the other methods. These other methods are the profit methods-subdivided in the profit split method and the comparable profits method - and the global formulary apportionment. The Discussion Draft of the OECD describes the pros and cons of the comparable profits method - with more cons than pros. At the final end that method is accepted for cases of last resort.

The difference is obvious, but all parties behave as if a harmonized result had been achieved. The first competent authority procedure concerning the application of the comparable profits method will demonstrate to what extent harmonization really has been reached. The European arbitration treaty has been ratified in the meantime. Therefore, in a foreseeable future we might get an arbitration decision on that subject, too.

After having 'solved' that conflict another one is knocking at the door. This one concerns the administrative burden for related companies. The conflict starts with the interpretation of the Best Method Rule. Under the US temporary regulations of 1993 the inapplicability of any other method did not have to be established $(\$ 1.482-1 \mathrm{~T}(\mathrm{~b})(2)(\mathrm{iii}))$. Under the final regulations 'in certain circumstances, it also may be relevant to consider whether the results of an analysis are consistent with the results of an analysis under another method' ( $\$ 1.482$ $1(\mathrm{c})$ ). This is already more demanding than before. Considering also the penalty regulations, a taxpayer can only avoid a penalty if he can prove that he has analyzed the other price 
methods and if he provides reasons for his actual choice. Therefore, the 'certain circumstances' have become a must!

The investigation of the data for all applied and not applied price methods already presents an extreme administrative burden for the industry. However, the additional documentation required to escape the penalties seems to be excessive.

Some of the OECD Member States share that opinion. Therefore, Chapter IV of the OECD report dealing with Documentation has not yet been published as a Discussion Draft. However, No. 85 of the OECD Discussion Draft clearly states that 'this report does not require either the tax examiner or taxpayer to perform analyses under more than one method'. To avoid an extreme administrative burden to the taxpayers the requirements for documentation should be governed by the principles of proportionality and reasonableness; the requirements should be reduced to the necessary minimum (as the Australian regulations expressly state). 